\title{
ENRIQUE FLÓREZ Y SUS CONTEMPORÁNEOS ANTE LA INTERVENCIÓN DE GREGORIO MAGNO EN OBISPADOS DE LA ESPAÑA BIZANTINA ${ }^{1}$
}

\author{
POR \\ Margartta Valléejo Girvés \\ Universidad de Alcalá de Henares
}

\section{RESUMEN}

El historiador agustino Enrique Flórez, con su obra Espaha Sagrada, domina la historiografia española del XVIII. Su análisis de la Spania bizantina es acertada en muchas $\propto$ casiones, pero carece de fundamento en otras. Algunos juicios históricos sobre hechos enmarcados en el período bizantino también pueden ser corregidos. En particular, las cartas que envió Gregorio Magno (560-604), mediando en una polémica eclesiástico-civil. Estas cartas, conservadas en el $R e$ gistrum Epistolaritum, fueron consideradas por Florez como obra de un falsario.

\section{Abstract}

Enrique Flórez and his contemporaneous historians in the face of Gregory the great's contribution to the polemic in the bishopships from the Byzantine Spain

Enrique Florez, agustinian historian, masters the spanish historiography from the XVIII ${ }^{\text {th }}$ century with his piece of work España Sagrada. His byzantine Spania analysis normally hits his tarjet, now and then may be wrong. Any historical inferences about the byzantine period can be revised. Particularly, concerning the letters that Gregory the Great (\$90-604) send, mediating in a civil-

1 Este artículo ha sido elaborado dentro del marco del Proyecto de Investigación La Real Academia de la Historia en la investigación hispana de los siglos XVII y XIX sobre la Historia Antigua y Medieval. financiado por la Universidad de Alcalá de Henares para el año 1996 (Ref. 026/96).

Cincuenta años Hispania Sacra 49 (1997) 
eclesiastical polemic. Those letters wore kept in the registrum epistolarium, and Flórez thought were written by a falsifier.

\section{INTRODUCCIÓN}

El panorama de la investigación histórica en la España del siglo XVIII está dominado, se quiera o no, por la figura del agustino Enrique Flórez, que con sus diversas obras pero especialmente con la que le otorgo fama internacional, la España Sagrada, parece marcar la pauta de la futura involucración de intelectuales y eruditos en la investigación sohre las épocas pasadas del quehacer hispano.

Aunque no es el momento de exponer pormenorizadamente la naturaleza e intención de la España Sagrada puesto que es sobradamente conocida por todos, recordaremos que más ạllá de lo que el título de la obra pueda indicar, estamos ante un análisis -en función del mapa episcopal hispano- de cualquier dato historico relativo a la zona de gobierno de esas sedes; ello hace que Flórez, y hablo ahora desde la perspectiva de mi campo de investigación, la Tardoantigüedad, comience su exposición por los hechos de la Historia Antigua de cada zona, lo que le conduce a ocuparse no sólo de la variante «cristianización» sino también de la esfera político-eclesiástica propiamente dicha; en efecto, el panorama episcopal hispano es, en buena parte, heredero directo de la situación que en ese mismo terreno organizativo se alcanza en la Antigüedad Tardía y concretamente durante el Reino Visigodo de Toledo, por lo que es lógico que los capítulos que Flórez dedica a la historia de esas sedes episcopales en la Antigüedad Tardía sean en muchas ocasiones si no los más amplios - algo por otra parte comprensible dada la poca documentación disponible en comparación con la que se posee para otros períodos- sí los más significativos. El que nos va a ocupar en esta ocasión es uno de ellos por la polémica provocada precisamente por la opinión de Flórez sobre el particular.

Cuando se utiliza para la investigación sobre la Spania bizantina la obra de Flórez, como ha sido mi caso ${ }^{2}$, salta a la vista que muchas de sus conclusiones fueron plenamente acertadas pero es igualmente palpable en sus escritos que otras carecen del mínimo fundamento, bien debido a apreciaciones erróneas de

2 Los datos, dada la estructura de la España Sagrada están dispersos en las diversas páginas que dedica a las sedes que tuvieron en un momento u otro relación con el gobierno bizantino en Hispania en los siglos V1 y VIl; los mas importantes son los volumenes V (Madrid 1751), VI (Madrid 1751), VII (Madrid 1752), VIII (Madrid 1752); X (Madrid 1753)), XII (Madrid 1754). Para las distintas ediciones que conocieron estos volúmenes, con indicación de las novedades presentes en ellas, vid. MARTínez AÑIBARRO, M., Intento de un diccionario biográfico o bibliográfico de autores de la Provincia de Burgos, Madrid 1889, pp. 213-23.

Cincuenta ẵos

Hispania Sacra 49 (1997) 
la documentación entonces disponible bien por otras diversas causas de varia naturaleza que abordaremos posteriormente ${ }^{3}$. Sin embargo, y como ya he dicho al principio, la autoridad de Flórez gozó en su época y en las siguientes -e incluso en algunas ocasiones aún hoy en día - de gran predicamento ${ }^{4}$, hasta el extremo de que se llegó a medir la validez de cualquier interpretación histórica en función de su correspondencia con las conclusiones sobre el particular emitidas por Flórez. Cierto es que su autoridad y su mérito son indubitables y así fue reconocido por las más insignes autoridades académicas de la Europa de la Ilustración, que le consideraron su corresponsal en España (así por ejemplo la Académie des Belles Lettres de París) ${ }^{5}$, pero no lo es menos que había en España intelectuales y eruditos que contestaban no pocas de sus afirmaciones 0 su método histórico e incluso su forma de citar las fuentes literarias que utili$\mathrm{za}^{6}$. No se puede negar que en la voluntad -al menos aparente- de Florez estaba el reconocer sus errores siempre que se le demostraran con argumentos de peso la falsedad de sus afirmaciones o la veracidad de una nueva propuesta; así lo expone en varias ocasiones, de las que destaca la que incluye en su Prólogo al primer tomo de su obra, y que extractamos por la contraposición que se puede hacer con otras opiniones que Flórez expresa en otros volúmenes posteriores y que afectan directamente al tema que aquí vamos a tratar: «Todo aquél que quisiese corregir en algún punto que tenga averiguado mejor que lo que yo le propongo, lisonjeará mi gusto si me instruyera en ello, para avisar al público en el tomo siguiente, y si no quiere darme cuenta, sino tomar por la suya el publicar la enmienda, reciba desde ahora mil gracias en mi nomhre, quedando yo gozoso de haber sido ocasión de que tengamos líquida una cosa. Mi intento es sólo contribuir en cuanto pueda al bien de nuestra Iglesia sin perdonar el trahajo de un casi perpetuo estudio. Lógrese éste mi deseo, mas que sea a costa

3 Esta opinión fue expresada ya por VIVES, JosÉ, Nuevas diócesis visigodas ante la invasión bizantina, Spanische Forschungen 17 (1961) 1, quien califica de «confusas» las páginas que dedica Flórez a la invasión bizantina de la Península Ibérica; đeja claro también Vives que muchas de las opiniones de Flórez -y de algún otro autor- se perpetuaron sin ser prácticamente revisadas.

4 Vid. sobre el particular SAGREDO FERNÁNDEZ, F., Enrique Flórez (1702-1773) y su España Sagrada, Homenaje a D. Agustín Millares Carlo I, Las Palmas 1975, pp. 517-8, e igualmente, aunque en un tono en absoluto partidista, MESTRE, A., Despotismo e llustración en España, Barcelona 1976, pp. 78-86.

5 En la Aprobación de Diego Regio al Tomo XII indica que «tengo entendido que ya las Naciones extranjeras han empezado a dar a conocer al mundo con aplauso el mérito de los libros de la España Sagrada en las Actas de los Eruditos de Lipsia y en las Memorias de Treboux». Igualmente SEMPERE Y GUARINOS, J., Ensayo de una Biblioteca Española de los Mejores Escritores del Reinado de Carlos III, Madrid 1785 (reimpr. Madrid 1969), 1, pp. 64, 76 y n. 1, se hace eco no ś́lo del gran predicamento hispano de su obra sino de ese reconocimiento internacional al consagrar un párrafo al elogio recibido del «Autor de la Biblioteca Eclesiástica Friburguense», quien sin embargo le reprocha que no esté escrita en latín.

G Vid infra. 


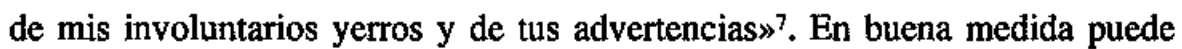
afirmarse que Florez fue fiel a este precepto inicial pues en su voluminosa obra están presentes las rectificaciones o contestaciones a algunas enmiendas que se le habían hecho por carta a algunas de sus opiniones ${ }^{8}$, pero también es cierto que hay ocasiones en las que se muestra reacio a contestar e incluso airado ante el hecho de que se le contradiga públicamente.

Su postura ante determinados acontecimientos emnarcados cronológicamente en el período en que el Imperio Bizantino dominó parte de las tierras de nuestra península también fue contestada; es en este contexto donde debemos situar el tema sobre el que queremos particularizar nuestro análisis puesto que se trata de unas contundentes respuestas contrarias a la opinión expresada por Flórez en el tomo 12 de la España Sagrada en el que cuestionaba abiertamente la veracidad de uno de los asuntos más importantes -dado su carácter político-eclesiástico- de los setenta años que duró la dominación bizantina en suelo peninsular. Es por ello por lo ante todo es necesario exponer cuáles son los datos y conclusiones de Flórez que merecieron primero una dura, documentada y bien orientada crítica en 1755 - aunque excesivamente farragosapor parte de Pedro de Castro, vicerrector del Colegio Español de San Clemente de Bolonia ${ }^{9}$ y tres décadas más tarde, en 1785 , una segunda, mucho más concisa, de Matías de Villanuñio, benedictino de Valladolid y continuador del proyecto de revisión de ediciones y del estudio de los documentos que en ellas aparecían iniciado por el también benedictino Ibarreta ${ }^{10}$.

7 España Sagrada (a partir de ahora ES) I, Madrid 1747 (sucesivas ediciones en $1754^{2}$ y $1789^{3}$ ) y vid. infra.

8 VegA, A. C., La España Sagrada y los Agustinos en la Real Academia de la Historia (Discurso leído el día 11 de junio de 1950 en su Recepción Pública), El Escorial 1950, pp.22-3.

9 La figura de Pedro de Castro (1721-1800) aunque no muy documentada, aparece relacionada con tres asuntos principales; el primero es su actuación como vicerrector del citado Colegio Español; el segundo es su criticada postura ante la práctica de la tortura a lo largo de la Historia de España; el tercero es el que nos ocupa aquí: sus publicaciones sobre el gobierno pontificio de Gregorio Magno. La participación de Pedro de Castro en la catalogación e inventario del archivo del Colegio Español de Bolonia deben tener mucho que ver con el conocimiento que muestra sobre esos temas (vid. infra). Sobre la figura de Pedro de Castro remitimos principalmente a PéreZ Martín, A., Proles Aegidiana 3. Los Colegiales desde 1600 a 1800 , Studia Albornotiana XXXI ${ }^{3}$, Bolonia 1979, pp. 1634-8; su participación en la ordenación archivística, donde ayuda y posteriormente continúa la labor de Pedro de Lafiguera puede verse en GIL. FERNÁNDEZ, L., De Codicibus albornotianis ad graecas latinisque litteras pertinentibus commentarius, Bolonia 1964, pp. 31-5 y en BERTRÁN ROIGÉ, P., Catálogo del Archivo del Colegio de España, Studia Albornotiana XL, Bolonia 1981, pp. 11, 20 y 54-5.

10 La obra en que se hace esta crítica a Flórez es Summa Conciliorum Hispaniae, siendo la única que aparece reseñada en el apartado que AGUILAR PIN̄AL, F., Bibliografia de autores españoles del siglo XVIII, Madrid 1995, vol. VIII, dedica a este benedictino; vid. también FERNÁNDEZ FLóREZ, J. A., La Congregación Benedictina de Valladolid en el s. XVIII, GIMENO BLAY, F. M. ed., Erudición y discurso histórico: las instituciones europeas (ss. XVIII-XIX), Valencia 1993, p. 124. Sobre la labor de

Cincuenta ađ̃os

Hispania Sacra 49 (1997) 
En el tomo 12 trata Enrique Florez, entre otras, de la sede malacitana; dicho obispado pertenecí al Imperio Bizantino desde el principio de su dominio hispano (552/555) hasta prácticamente los últimos años del mismo, puesto que no fue conquistado para el Reino Visigodo hasta las campañas béticas de Sisebuto $^{11}$. La historia imperial de este obispado es en consecuencia larga -por supuesto relativizándola en función de la duración del gobierno bizantino en áreas hispanas-, pero lo que le otorgó un mayor carácter y proyección histórica dentro del acontecer de la Iglesia española tardoantigua fue la actitud de uno de sus obispos ante el gobierno del Imperio; los hechos y documentos, datables a finales del siglo vi, sobre los que Florez emite opinion y sobre los que Pedro de Castro y Matías de Villanuño le rectifican son los siguientes:

En el Registrum Epistolarum de Gregorio Magno (590-604) aparecen varias cartas referentes a una grave polémica eclesiástico-civil que afectó a dos obispos hispanos de dependencia bizantina y que motivó la intervención en el asunto de Gregorio Magno ${ }^{12}$, aunque sólo conocemos los hechos sobre los que el Papa se ve obligado a intervenir de modo indirecto, precisamente a través del análisis papal de los mismos. En sí, de estos documentos se comprende que Comitiolus, un individuo de algo rango -es llamado Gloriosus-, gobemador de los territorios hispanos del Imperio expulsa de su Iglesia y depone de su sede al prelado de la sede malacitana de nombre Ianuario y hace que otros obispos nombren a otro en su lugar; de la misma forma este Comitiolus hace juzgar a Esteban, también obispo hispano de obediencia imperial y de sede desconocida, utilizando en su contra el testimonio de los servidores de ese prelado, con lo que le depone de su sede y le exilia. Intuimos por las cartas de Gregorio Magno que la acusación que pesaría sobre los obispos sería de Lesa Majestad y también sabemos que la intervención del pontífice responde a la apelación que estos obispos hacen a la máxima jerarquía eclesiástica de la Iglesia de Occidente, esto es el Papa, que como ellos era, además, súbdito del Imperio Bizantino pues recordemos que Málaga - la única sede de nombre conocido de las dos involu-

los benedictinos de Valladolid, DUBUIS, M., L'Espagne et Saint-Maur, la congregation de Valladolid dans le mouvement erudit entre 1670 et 1790, París 1982, amén de la muy reciente publicación del Dr. A. Linage Conde dedicada a la historia de los benedictinos en Espafia.

11 VALLEJO GIRVÉS, M., Bizancio y la España Tardoantigua. Ss. VI-VIII. Un capítulo de historia mediterránea, Memorias del Seminario de Historia Antigua IV, Alcalá de Henares 1993, pp. 114-7, 143-51 y $288-97$.

12 Gregorio MAgNo, Reg. Epist. XIII, 46, 48 y 49 de la ed. NORBERG, D., Sancti Gregori Magni Registrum Epistolarum (CCL, 140-140A), Turnholt 1982, que se corresponden con las XIII, 47, 49 y 50 de Registrum Epistolarum, en MGH Epistolarum I-II, ed. EWALD, P. y HARTMANN, L. M., Berlín 1891-1899 (reimpr. Munich 1978) y la XIII, 50, de la ed. de los benedictinos de San Mauro de principios del XVIII, que es la que utilizan Florez y Castro; ambos incluyen también otra numeración -antecedida con el adverbio olim- correspondiente a una edición anterior que no especifican. 
cradas en el asunto- y Roma, la sede papal, eran a finales del siglo vi posesiones del Imperio Bizantino en el Occidente del Mediterráneo ${ }^{13}$.

Entre las páginas 312 a 319 (parágrafos 64 a 71) del Tomo XII, Flórez ${ }^{14}$ expone los motivos por los que cree que aunque pueda haber algunos datos ciertos en esos episodios que hemos resumido -en concreto no duda de la existencia de un obispo malacitano de ese nombre para esas fechas finales del siglo VI ni tampoco de la verdad de la presencia del responsable de la deposición puesto que está documentada en una inscripción encontrada en Cartagena-1s considera que hay muchos elementos en esas cartas, extrínsecos e intrínsecos, que imposibilitan que se hubieran producido tales acontecimientos y en consecuencia concluye que las cartas sobre este tema incluidas en los códices que contienen el Registrum Epistolarum de Gregorio Magno - se trata de los llamados capitulares (XIII, 46), sententiae formula (XIII, 48) y exemplum legis (XIII, 49) - son obra de un falsario ${ }^{16}$; en sí los argumentos que Flórez utiliza para apoyar o defender la idea de que estos documentos de Gregoria Magno que afectan a las autoridades civiles y eclesiásticas de la Spania bizantina son cuanto menos dudosos son los siguientes:

1. Considera que no es lógico que no exista sentencia de la intervención de Gregorio sino únicamente un formulario en el que no se especifica nada de la situación personal de ambos prelados. Lo correcto para Flórez, y

13 Sobre este particular me he ocupado en Bizancio y la España Tardoantigua..., pp. 415-25; Bizancio ante la conversión de los Visigodos: Los obispos Jenaro y Esteban, Actas del XIV Centenario Concilio III de Toledo. 589-1989, Toledo 1989 (1991), pp. 477-83; The Byzantine and Visigothic Perspective of the Political and Religious Context at the End of the Sixth Century, Abstracts of Papers. Byzantine Studies Conference, New York 1995, p. 92 y de un modo mas extenso en Comenciolus, magister militum Spaniae, missus a Mauricio Augusto contra hostes barbaros. The Byzantine Perspective of the Visigothic Conversion to Catholicism, RomanoBarbarica 14 (en prensa).

I4 FLÓREZ, E., España Sagrada XII. De las Iglesias sufragáneas antiguas de Sevilla: Egabro, Elepla, Eliberi, Itálica, Málaga y Tucci, Madrid 1754.

is ES XII, 313, par. 65 a 67, donde expone los datos que él cree fiables, y que son esencialmente la presencia de Comentiolo y la posibilidad de que el sucesor de Severo en la sede malacitana (Isid., De Virs. IIIs. XXX) se llamara Ianuario. La inscripción de la que habla es $C I L I, 3420$; se trata del epígrafe monumental que describe parte de las fortificaciones de Carthago Spartaria, entonces en manos del Imperio y donde se lanza un evidente mensaje ideológico para concienciar a sus súbditos hispanos contra el Reino Visigodo, una vez que había quedado anulado, por mor de la conversión de Recaredo, el factor religioso (arrianismo-catolicismo) como elemento diferenciador entre la zona visigoda y la bizantina; vid. VALLEJo GIRvÉs, M., Comitiolus..., en prensa.

16 ES XII, 313, par. 65; es necesario dejar constancia que existen algunas epistolae incluidas en algunos códices que contienen el corpus epistolar gregoriano que están duplicadas o son manifiestamente falsas, corno es conocido desde hace muchos siglos (MINARD, P., Grégoire le Grand. Registre des Lettres. Introduction, texte, traduction, notes et appendices, I, Paris 1991 (Col. Sourches Chretiennes), pp. 54 y 58.

Cincuenta ar̃os

Hispania Sacra 49 (1997) 
entonces sí sería verdadero ese documento, hubiera sido que la sentencia estuviera particularizada y que no se tratara únicamente de instrucciones a su enviado a la Península.

2. Añade a esa razón el hecho de considerar mal colocadas por la fecha de la indicción las cartas dentro del Corpus del Registrum Epistolarum ${ }^{17}$.

3. El hecho de que se alegue para invalidar la deposición y los juicios a que estos fueron hechos por obispos de otra provincia - se trata de la conocida expresión ab alieni concilii- la juzga Flórez totalmente alejada de la realidad de la Spania bizantina a finales del siglo $\mathrm{VI}^{18}$.

4. Considera que es una total incongruencia con la práctica de la época el que el Papado utilice para emitir sus juicios leyes civiles, como las del Codex Theodosianus o alguna Novella justinianea y no utilice la legislación eclesiástica.

5. Por áltimo pero relacionado en ciertos aspectos con el punto anterior, nos habla de la existencia en estos documentos de «otras incongruencias», tales como la imposibilidad de que Gregorio Magno utilizara la documentación legal justinianea porque el Papa no conocía el griego ni había traducción latina de la misma (?).

No nos detendremos ahora en las verdades del razonamiento de Flórez si bien anticipo que su perspectiva en esta ocasión parece absolutamente equivocada, especialmente en el punto al que dedica mayor atención: el formulariosentencia ${ }^{19}$. Aquí nos interesan tanto los argumentos del agustino como sus lecturas puesto que nos dice que no es suya la responsabilidad de la primera negación de tal veracidad, aunque asume sus propuestas y argumenta como hemos visto sobre el particular; la responsabilidad sería, según Flórez, de una Disertación de la que curiosamente omite el nombre de su autor y que define con las siguientes palabras: «Sobre estas Cartas de San Gregorio he visto, y tengo una Dissertación, compuesta a fin de mostrar no ser legítimas» ${ }^{20}$. Puesto que la responsabilidad primera no es de Florez sino del autor de la citada Disertación, procede averiguar la autoridad de la misma, siendo éste un aspecto fundamental de nuestro análisis porque es curiosamente Pedro de Castro, el primer autor que va a corregir a Flórez sobre este particular, el que se da por

17 ES XII, par. 68.

18 ES XII, par. 69-70.

19 Remitimos a VALlejo GiRVÉs, M., op. cit., loc. cit.

20 ES XII, 313, par. 65. 
aludido y cree que se le considera el responsahle de la difamación de la obra gregoriana ${ }^{21}$.

Puesto que el tomo XII de la España Sagrada recibe las aprobaciones y censuras favorables entre mayo y junio de $1754^{22}$, la Disertación responsable de haber provocado la duda en Flórez tiene que ser anterior a la primavera de ese año 1754, pero forzosamente contemporánea de Flórez y Castro porque de lo contrario habría sido conocida con anterioridad y no habría lugar a que se le atribuyera al segundo. El autor de la España Sagrada dice poseer esta Disertación, que dado que se hizo ex profeso para demostrar la falsedad de las cartas, debería incluir en el título alguna referencia al tema en sí o a sus protagonistas; afortunadamente se nos ha conservado el catálogo de la Biblioteca de Enrique Flórez, así que, puesto que dice poseer la misma, es por allí por donde procede comenzar la búsqueda de esta polémica obra cuestionadora de la intervención de Gregorio Magno en obispados pertenecientes a la provincia bizantina de Spania.

Es muy amplio el catálogo en $\mathbf{s i ́}^{23}$ pero obras que pudieran referirse a algunos de estos aspectos no lo son; pueden dividirse en dos categorías. Por un lado las ediciones de las obras de Gregorio Magno, con la más reciente edición de la obra completa del Pontífice, publicada por los benedictinos de San Mauro en los primeros años del siglo $\mathrm{XVIII}^{24}$ y sus Epistolae en el modo en que Martín Bouquet las incluye en su obra sobre los escritores de Galia y Francia, obra por cierto elaborada también en la primera mitad del siglo XVIII ${ }^{25}$. Por otro lado se encuentran las obras que se refieren a algún aspecto concreto de la obra de Gregorio Magno; son dos y curiosamente ambas del autor que le corrige en primera instancia, Pedro de Castro. Una de ellas es precisamente la contestación a Flórez, publicada en 1755, de la que nos ocuparemos más adelante, y la otra, de 1753, se titula Epistola ad Monachos Benedictinos Congregationis Parisiensis Sancti Mauri super quibusdam parum consonis, praetermissis,

\footnotetext{
2I Vid. infra.

22 Sabemos además por una carta que Flórez dirige a Patricio Gutiérrez Bravo el 18 de junio de 1754 que en ese mismo mes se iba a comenzar la impresión de ese tomo; vid. RODRíGUEZ MOŇiNO, A., Epistolario del P. Flórez con Patricio Gutierrez Bravo (1753-1773), BRAH CXXXIV, 1954, p. 409.

23 VeGA, A. C., Catálogo de la Biblioteca del Padre Enrique Flórez, BRAH CXXVIIII, 1951; CXXIX, 1951; CXXX, 1952; CXXX, 1952; el original del catálogo se encuentra en la Biblioteca de la RAH de Madrid.

24 Aparece como S. Gregorii Papae I. cognomento Magni. Opera omnia. Notis illustrata Studio et labore Monachorum Congregationis S. Mauri, París 1701 y \$s.

25 En el catálogo aparece enunciada de la siguiente forma: Epistolae, vid. T. 4 de Bouquet de los Escritores de Francia.
}

Cincuenta años

Hispania Sacra 49 (1997) 
atque improbabilibus in vita Sancti Gregorii Magni ab ipsis adornata, et in Tomo IV. operum in lucem edita repertis ${ }^{26}$.

Pedro de Castro en el prólogo de la obra en contestación a Flórez, titulada Dissertación apologética de la legitimidad de los Capitulares de San Gregorio Magno a Juan Defensor, sobre la deposición de los obispos de España, indica que se le ha atribuido por parte de algunos de sus contemporáneos la autoría de la Disertación que Flórez cita, precisamente porque se ocupó de la obra de Gregorio Magno en 1753: «No sería extraño el que ahora me bubieses juzgado Autor de la Disertación, que en esta impugno pues habiéndome yo manifestado al público en Diciembre de 53, algo instruido en las obras de San Gregorio Magno, y no expresando el Rmo. Flórez al tratar de Januario, Obispo de Málaga, en su Tomo 12 de la España Sagrada, publicado en Enero de este presente año, el nombre del Autor de la Disertación, que le inclinó a tener por ilegítimos los documentos, que aquí defiendo, no ha faltado entre los sujetos, que el Rmo. elogia en su obra, quien con tan gráve fundamento ha tenido por mía la Disertación, que allí se cita» ${ }^{27}$, en consecuencia hay que pensar que alguna relación previa a ese 1755 habría tenido Pedro de Castro con la obra de Gregorio Magno y que esta relación habría sido publicada ya que de otro modo no se entendería la actitud de esos sujetos.

La relación que nosotros conocemos de Pedro de Castro con la obra de Gregorio Magno en 1753 es la Epistola ad Monachos, en la que hace una serie de puntualizaciones a la edición de los benedictinos de San Mauro sobre documentos relacionados con Gregorio Magno -especialmente con sus Epistolae pero también con las diversas Vitae compuestas sobre su persona- en función de las lecturas que habría hecho en el códice que del Registrum Epistolarum de ese pontífice poseía la Biblioteca del Colegio Español de San Clemente de Bolonia ${ }^{28}$, por lo que cabría pensar que esta obrita fuera la causante de

26 En el catálogo aparece como: CASTRO, P., Epistole ad Monachos Benedictionos congregationis S. Maurit super quibusdam praeterminis in Vite S. Gregorii Magni, Madrid 1753 (conoce otra edición en Bolonia en 1754). Se inscribira posiblemente esta Epistola en una costumbre fomentada por los mauristas de intercambiar opiniones sobre los temas en los que estaban trabajando con los intelectuales de Europa; vid. GASNAULT, P., Le correspondance des mauristes aux XVHè. et XVHİ. siècles, Sous la Règle de Saint Benoît. Structures monastiques et sociétés en France du Moyen Âge d l'époque moderne, París-Ginebra 1982, pp. 293-302, y brevemente LiNAGE CondE, A., Los Mauristas o Maurinos, Medievalismo I (1991) 143.

27 CASTRO, P. DE, Disertación apologética de la legitimidad de los Capitulares de San Gregorio Magno a Juan Defensor, sobre la deposición de dos obispos de España, Madrid 1755, prólogo, sin paginación. Por cierto que aquí concreta un poco mas sus referencias a quienes son los responsables de tal atribución, que considera ofensiva; los responsables son individuos que el $*$ Rmo. elogia en su obram.

28 En esta Epistola dice haberlo consultado un año antes, por lo tanto debería ser en 1752, año en que consta que estuvo en Bolonia (PÉREZ MARTín, A., op. cit., p. 1637, y Gil FERNÁNDEZ, L., op. 
la «errónea atribución» a Pedro de Castro de la Disertación contra los capitulares de Gregorio Magno que maneja Flórez en su tomo XII de la España Sagrada.

Sin embargo el propio Castro, con una indignación nada disimulada, reacciona ante esa atribución con la dura publicación de la Disertación Apologética, continuando en el Prólogo: "si el Autor de ella no quiere que como a tal se le conozca, tampoco quiero yo que se me atribuya ${ }^{29}$, por lo que en consecuencia quedan varias cuestiones sin resolver: Si Pedro de Castro niega ser el autor -así parece al menos- y parece desconocer también tal Disertación y como parece que nada hay en la Epistola ad Monachos que justifique tal atribución, ¿cuál es la razón por la que la crítica se la atribuye?, ¿de quién es esa polémica obra? y ¿por qué calla Flórez el nombre del autor?, en definitiva ¿existió realmente la misma?

Lo único cierto es que Pedro de Castro se da inmediatamente por aludido, razón por la que constnuye un largo y ampuloso discurso destinado principalmente a defender la autenticidad de la documentación que Florez cuestionaba abiertamente, pero también destinado a llamar la atención sobre el excesivo seguimiento que tenía en su opinión cualquier propuesta del augustino. Es momento por lo tanto de centrarnos en la «enmienda» que le hace Pedro de Castro nada menos que con ochenta y siete páginas más diez de apéndices. Los argumentos de Pedro de Castro son:

1. Los documentos no pueden ser falsos porque aunque es cierto que no están presentes en todos los códices conocidos del Registrum Epistolarum, figuran en la inmensa mayoría de ellos ${ }^{30}$.

2. No puede tratarse de una falsificación porque las referencias a este episodio hispano ya aparecen en la Vita Gregorii Magni compuesta en el siglo IX por Juan Diácono ${ }^{31}$; es más, puesto que son muchos los autores antiguos que las citan, debe deducirse de ello su autenticidad ${ }^{32}$.

3. Todas las cartas corresponden realmente a la VI Indicción y a ello debe unirse otro mensaje hacia Hispania, la carta en la que el Defensor debe visitar Capraria, viaje que por cierto Flórez no cuestiona ${ }^{33}$.

\footnotetext{
cit., p. 34: se trata del Ms. 8). Sobre las características de este códice, al que llama «Albornociano», remitimos a HARTMANN, L. M. ed., Gregorii I Papae. Registrum Epistolarum. T. II. Libri VIII-XIV cum indicibus et Praefatione, Berlín 1899 (reimp. Munich 1978) (MGH Epistolae I), p. XI.

29 En la obra aparece sin paginación.

30 CASTRO, P. DE, Disertación..., parágrafos 1 a 7.

31 CASTRO, P. DE, Disertación..., par. 8 a 11.

32 CASTRO, P. DE, Disertación..., 14.

33 CASTRO, P. DE, Disertación.... par. 12.

Cincuenta años

Hispania Sacra 49 (1997)
} 
4. No es un unicum la utilización del término Capitulares en la obra de Gregorio Magno ${ }^{34}$.

5. Discutiendo en torno a la cronología de los hechos en cuestión y en torno a la visita de delegados papales a Málaga, concluye que esas visitas estarian ya relacionadas con el asunto de Ianuario ${ }^{35}$ ya que de lo contrario no se comprendería tal asiduidad.

6. Se analiza aquí un punto sobre el que ha habido multitud de errores puesto que plantea para justificar la intervención directa de Gregorio Magno respondiendo a la apelación, el grado de autoridad que tendría el Reino Visigodo y Leandro de Sevilla en particular sobre los prelados sujetos al gobierno bizantino ${ }^{36}$.

7. Contestando a Flórez sobre la inconsistencia de las instrucciones dadas a Juan Defensor, expone que se trata de un «formulario», un tipo de documento nada extraño en la correspondencia de este pontífice (lo ejemplifica adecuadamente), concluyendo que sólo se facilita el formulario para que el enviado papal lo cumplimente en función de los datos concretos de cada caso ${ }^{37}$.

Queda claro de la exposición de Pedro de Castro y de la ingente documentación que utiliza para demostrar su criterio que no se trataba de alguien que estaba caminando por un terreno desconocido. Por el contrario, este autor acude precisamente a aquellos documentos y situaciones precisos para dejar de manifiesto que nada había de extraño en tal intervención de Gregorio Magno en un obispado hispano sujeto al control de Constantinopla viéndolo desde el contexto de su gobiemo sobre el resto de las Iglesias occidentales pero también desde su posición de súbdito del Imperio, y en consecuencia defiende Pedro de Castro la autenticidad de los documentos y la veracidad de la situación que se comprende de los mismos; como ya he dicho, sin duda su activa participación en la ordenación del archivo del Colegio Español de Bolonia tienen mucho que ver con esa actitud exhaustiva de Castro a la hora de proporcionar documentos y lecturas diversas de los mismos pues de hecho sabemos que era un consumado lector de las sucesivas ediciones de las obras manuscritas que poseía el Colegio ya que en varias de ellas dejó anotadas las variantes

34 CASTRO, P. DE, Disertación..., 13.

35 CASTRO, P. DE, Disertación... 15-33; Esta es una de las argumentaciones más confusas del autor.

36 CASTRO, P. DE, Disertación..., par. 35-48.

37 CASTRO, P. DE, Disertación..., pár. 49-55. 
que presentaban con sus ediciones impresas ${ }^{38}$. Tal vez sea en el aparentemente menor manejo de documentos -amén del momento por el que pasaba la intelectualidad hispana sensibilizada ante la multitud de falsificaciones perpetradas en las siglos anteriores 39 - de lo que puede derivar esa actitud excesivamente crítica de Flórez sobre la intervención de Gregorio Magno en obispados de la Spania bizantina.

Pedro de Castro una y otra vez provoca a Flórez, y no sólo en el Prólogo sino en varias páginas de su libro, siendo tal vez la más significativa una que está dirigida no tanto contra el agustino sino contra los que seguían sin discusión cualquiera de sus propuestas. En concreto en el parágrafo 33 de su Disertación expresa que se ha visto obligado a llevar a cabo esta defensa de los «Capitulares gregorianos» porque «no ignoro lo mucho que pesa para con los más la autoridad del Reverendísimo Flórez, y con razón; porque siendo su erudición tan vasta, a no alegar yo tal multitud de pruebas convincentes, se entendería sin duda en los siguientes escritos su opinión; y se daría por apócrifo cualquier documento, que pueda hallarse...».Tales provocaciones buscarían lógicamente lograr una contestación por parte de Flórez, ya que no eran pocas las ocasiones en las que el agustino se había hecho eco de las críticas o matizaciones que habían recibido sus respuestas sus propuestas y o bien las había aceptado o bien rebatido de nuevo incluyéndolas en las sucesivos tomos de la España Sagrada; es más, como hemos visto el propio Flórez impulsaba en su tomo I a que se analizaran sus propuestas e incluso «aprobaba» una publicación independiente con ellas ${ }^{40}$. Sin embargo en esta ocasión Flórez dio la callada por respuesta aun tratándose de un ataque directo contra la línea de flotación de su discurso; únicamente encontramos en los volúmenes posteriores de la España Sagrada un párrafo que veladamente podría aludir a este ataque de Pedro de Castro:

En las páginas que dedica a las «correcciones» en el tomo XIII de la España Sagrada que ve la luz un año después de la Disertación Apologética de Pedro de Castro, encontramos el discurso siguiente, de carácter críptico pero que creo que puede estar precisamente relacionado con la polémica que quiso emprender el colegial de Bolonia: «Algunos de los que tuvieron noticia de mi indisposición, han creído ser ella la causa de que no respondiese a unos Papeles publicados sobre puntos tocados en mis libros. Mas no ha sido éste el motivo, sino el expresado en la Respuesta a la Carta de D. Juanchin de Azur,

38 Seguimos siempre aquí a PÉrez MARTín, A., op. cit., p. 1635, n. 6 ,y a GIL FERNÁNDEZ, L., op. cit., p. 35, pues precisamente uno de los manuscritos que presenta las «huellas cotejadoras" de Pedro de Castro es el Ms. 8, el del Registrum Epistolarum de Gregorio Magno.

39 VEGA, A. C., op. cit., pp. 24-7 y n. 12-5.

40 Vid. supra.

Cincuenta años

Hispania Sacra 49 (1997) 
donde previne al público en adelante no desperdiciaría las horas sobre ocios ajenos, y que por tanto ninguno se juzgase desairado al ver que se queda sin respuesta ${ }^{41}$ : pues sabiendo mi prontitud a corregir cuanto se conozca estar errado, será la emulación quien los aliente, no el amor a la pública utilidad; y así reciban desde ahora mi Vale. Esto dije en el año de 1752, y esto vuelvo a decir, porque no habiéndome manifestado ninguno los fundamentos que tuviese, para mostrar ser falso mi sentir: es prueba el dar a luz su intento lo hicieron por buscavida. tomándole por medio para lo que imaginaron oportuno: $y$ por mí tienen el paso franco, pues ni he leído, ni leeré lo que venga por semejantes medios: y al contrario para corregir mis yerros me basta cualquier prevención familiar en que me haga fuerza la razón, como convencen los Tomos precedentes, y lo que ahora, continuando su práctica, corrijo sobre el Tomo XII.... ${ }^{42} \mathrm{Si}$ de este texto puede comprenderse, así lo creo, una alusión a las duras críticas de Pedro de Castro, parece evidente que sus argumentos entrarían entre los que Flórez consideraría errados y que en nada enmendarían a los suyos ya que ni tan siquiera acusa recibo directo de los mismos ${ }^{43}$; no fue de todos modos muy afortunado Pedro de Castro a la hora de lograr que los que había provocado con sus obras le respondieran, posiblemente porque muchos de ellos interpretaron su postura como excesivamente arrogante, tal como lo podemos ver en uno de sus contemporáneos quien nos dice «ni le han respondido (acaso porque lo han despreciado) ${ }^{44}$.

En 1773 fallece Enrique Flórez, pero casi diez años más tarde nos topamos nuevamente con otra contestación contraria a su propuesta sobre la falsedad de

${ }_{41}$ Se refiere aquí a Respuesta del M. R. P. Maestro Enrique Flórez a la carta publicada bajo el nombre de Dn. Juachin de Azur, Madrid 1752, p. 55, par. 50; Juachin de Azur es el seudónimo de Juan de Chindurza, fiscal de Indias, que había contestado a Flórez exponiendo algunos reparos a sus argumentos del tomo VIl de la Espania Sagrada, tambien en parte dedicada a la «historia bizantina», de algunos obispados hispanos (Carta de Dn. Juachin de Azur al R. P. M. Fray Enrique Flórez, exponiendo algunos reparos sobre el tomo séptimo de la España Sagrada. Madrid 1752; concretamente le criticaba -aunque no siempre con razón- su forma de citar los códices y las fuentes, la ausencia de ediciones recientes, su forma de escribir, de interpretar las inscripciones, y algo que nos interesa especialmente: la relación entre las sedes de Carthago Spartaria, Begastri, Mlici y Elota en la época visigodo-bizantina).

42 FLÓREZ, E., ES XIII, Madrid 1756, 3 verso.

43 De todas formas, considero que de la respuesta a Azur (especialmente pp. 3-4) y de este prólogo al tomo XIII de la ES se deduce el desagrado que sentía Flórez a que le hicieran correcciones públicas y publicadas sin habérsele comunicado previamente los argumentos y esa intención; opinión contraria en SALVADOR Y BARRERA, J. M., El Padre Flórez y su España Sagrada. Discurso Leído en la RAH el I de marzo de 1914, Madrid 1914 (en la Ciudad de Dios XCVII (1914) 5-21, 91-8), y VEGA, A. C., op. cit., p. 30.

44 SEMPERE Y GUARINOS, J., op. cit, p. 179-80, en relación a la polémica, ésta sí bien documentada, que crea con su estudio sobre la tortura en la historia de España (cf. SARRAILH, J., La España ilustrada de la segunda mitad del siglo XVIII, trad. esp. Madrid 1985, p. 583). 
los documentos que hablaban de la intervención de Gregorio Magno en la España bizantina; en esta ocasión es obra de Matías de Villanuño con quien al parecer Florez ya habría tenido divergencias a causa de unos documentos relativos a Balconio de Braga ${ }^{45}$.

Como ya he dicho, Villanuno es el responsable de la compilación Summa Conciliorum Hispaniae ${ }^{46}$, obra en la que no sólo se consignaban los documentos conciliares sino que se estudiaban aquéllos relacionados con la historia de la Iglesia hispana que habían ocasionado alguna discusión o divergencia intelectual o doctrinal. Uno de los documentos que es objeto de estudio particular son las cartas de Gregorio Magno a Juan Defensor, precisamente teniendo este estudio como punto central el demostrar lo errado de las conclusiones de Flórez.

Es mucho más breve la argumentación de Villanuño puesto que sólo ocupa tres páginas y también es mucho menos ampulosa que la de Pedro de Castro pero sin embargo sus argumentos son parejos y la intención de dejar claro que Flórez no siempre tenía razón también está presente en Villanuño, si bien es imposible que el agustino le respondiera.

Basaba Villanuño su argumentación especialmente en el punto que estaba más relacionado con la naturaleza de su obra: los aspectos canónicos o legales, así que a la idea de Flórez de que la ausencia de leyes eclesiásticas en las instrucciones dadas por Gregorio Magno eran un indicio de la falsedad del documento en cuestión, oponía Villanuño el hecho de que puesto que se había tratado de una deposición provocada o auspiciada por un gobernador del Imperio, era plenamente adecuada la utilización de leyes civiles ${ }^{47}$; añadía a ello además varios ejemplos de casos en los que la Iglesia y e] Papado habían utilizado las leyes imperiales en sus sentencias ${ }^{48}$. A lo que Flórez consideraba «torpe ignorancia» del autor del documento conocido como sententia por no haber concretado los datos sobre los que se iba a dictar sentencia, opone Villanuño según él, o bien Flórez no había leído las cartas sino que lo habrían hecho otros ojos o bien que el agustino había hecho una lectura excesivamente rápida de las mismas - la idea ya apuntada por Castro de que realmente se trataba de un «formulario», uno más de los muchos que existían en la Cancillería papal ${ }^{49}$.

\footnotetext{
45 Vid. FUENTE, V. DE LA, Historia Eclesiástica de España, I, Madrid 1880, p. 214 y II, Madrid $1883^{2}$, p. 65 y n. 1 .

46 Summa Conciliroum Hispaniae. Quotquot inveniri potuerunt ad usque saeculum proxime praeteritum. Notis novisque dissertationibus adornata. Opera et Studio, I, Madrid 1785.

47 VILLANUÑO, M. DE, op. cit., p. 370.

48 VILlANUÑo, M. DE, op. cit., p. 371.

4 Muy relacionado todo ello con el Liber Diurnus; vid. SinsSCALCo, P.; PIZZARI, U., BERardino, A. DI, «Scrittori dell'Italia», en Berardino, A. ed., Patrologia $W$. Dal Concilio di Calce-
}

Cincuenta aftos

Hispania Sacra 49 (1997) 
En lo único que en mi opinión no debió enmendar Villanuño a Flórez fue en la fecha propuesta para el acontecimiento que el segundo situaba - a pesar de que negaba su autenticidad, databa los acontecimientos-en época de Recaredo (y Mauricio) y Villanuño en época de su hijo Liuva y de Witerico: por razones que sería excesivamente largo enumerar aquí, considero que las circunstancias políticas del Reino Visigodo y del Imperio Bizantino en la última década del siglo VI hacen que este hecho sea más factible entonces que no en plena época conflictiva en el seno del Imperio, con Focas a la cabeza; otra cosa es que el Papa se decidiera a intervenir en ese asunto de la Iglesia bizantina de Spania bajo el gobierno de Focas puesto que iba a tomar una decisión contraria a Mauricio, el emperador ejecutado precisamente por el que ahora detentaba el poder en el Imperio, puesto que no debería temer una reacción del emperador al dictar una resolución contraria a la actuación de uno de los oficiales más fieles del anterior emperador ${ }^{50}$.

La enmienda de Villanuño es tres décadas posterior a la de Pedro de Castro y sin embargo en ningún momento hace alusión el primero a la obra del de Bolonia $^{51}$, dato que considero altamente extraño y al que únicamente encuentro una explicación: la intención de Villanuño de monopolizar la polémica con Flórez porque repito que a pesar de lo confuso o complicado de su discurso, la obra de Pedro de Castro es sumamente concluyente y no debió ser ignorada en ningún momento.

Exceptuando las obras que junto a la de Flórez hemos analizado aquí, la historiografía posterior no parece haber prestado mucha atención a la propuesta falsedad en cuestión porque nadie después de Flórez parece haber dudado de la autenticidad de las citadas Epistolae; a modo de ejemplo comentaremos los pasajes de la obra del crítico jesuita Juan Francisco Masdeu dedicados a este episodio particular: este autor publica su Historia Crítica de España y la Cultura Española a finales del siglo XVIII y conoce la obra de Flórez porque la cita pero en ningún momento alude a la propuesta falsedad de los documentos que nos ocupan, que utiliza dándoles plena validez en el volumen XI (el tercero dedicado a la España Goda), ni por supuesto a las propuestas contrarias de Pedro de Castro y de Matías de Villanuño, y sí sin embargo discute opiniones de autores anteriores a él que proponían diversas dependencias me-

\footnotetext{
doia (451) a Beda. I Padri Latini, Roma 1996, pp. 147-8 y 169; MiNARD, P., op. cit., p. 52-6, y NORBERG, D., Qui a composé des lettres de s. Grégoire le Grand, StudiMed. XXI, I (1980) 1-18. 50 VALLEJO GIRVÉS, M., op. cit., pp. 415-525.

51 Aunque tampoco menciona esa disertación misteriosa que precedió a Florez en esa duda.
} 
tropolitanas para Ianuario y Esteban, en función de la información que proporciona los documentos que ahora nos ocupan ${ }^{52}$.

No es sino en las últimas décadas del siglo XIX cuando volvemos a encontrar algún eco, aunque débil de la polémica entre Flórez y sus contemporáneos sobre la veracidad de la intervención papal en asuntos de la jerarquía eclesiástica de la Spania bizantina. Son tres los ecos que conocemos; el primero es obra de un autor español, Vicente de la Fuente; los dos restantes son obra de extranjeros, concretamente alemanes: P. B. Gams y P. Ewald, siendo más amplia la merición del segundo.

En 1873 aparece la segunda edición del tomo que Vicente de la Fuente dedica en su obra Historia Eclesiástica de España a la historia eclesiástica hispano-visigoda, que cubre un período cronológico entre el 409 y 711 . Una parte de la Historia es lógicamente la "venida de Juan Defensor a España» ${ }^{53}$, puesto que viene a ilustrar la relación entre el Papado y los diversos obispados hispanos en la Antigüedad Tardía.

Vicente de la Fuente conoce la negación de Flórez sobre su venida y el asunto a resolver —así lo indica en estas páginas ${ }^{54}$ —, también conoce la obra de Pedro de Castro puesto que el capítulo se abre con la mención de su Disertación en el apartado Tratados sobre las fuentes, así como la obra de Villanuño, que cita en nota. Sin embargo no deja de causar perplejidad que la cita inicial de la obra de Pedro de Castro sea el único uso que Vicente de la Fuente hace de ella ya que cuando aborda la propuesta de Flórez de que no puede tratarse de un documento auténtico únicamente consigna - por cierto en una nota-: «Flórez, apoyándose en la mucha importancia que da el Papa a las leyes civiles, niega la legitimidad de este documento; y Villanuño lo defiende contra Flórez con razones convincentes» ${ }^{55}$.

Es cierto que Villanuño utiliza «razones convincentes» pero también lo hace Pedro de Castro tres décadas antes y en vida de Flórez. Vicente de la Fuente conoce la obra pero no la utiliza: la explicación a ello tal vez resida en la brevedad y contundencia - aunque menos documentada que la de Pedro de Castro-- de la exposición de Villanuño y en una circunstancia que ya he indicado más arriba: lo complejo del discurso de Pedro de Castro, al que sin embargo no

52 MASDEU, J. F., Historia Crítica de España y de la Cultura Española. XI. España Goda II, Madrid 1792, pp. 86-7 y 157-9.

53 FUENTE, V. DE LA, op. cit., II, pp. 199-203, par. 60.

54 Flórez aparece también en la obra de V. de la Fuente como el responsable primero de este cuestionamiento, ya que en ningún momento alude a esa misteriosa disertación que Flórez decía poseer, algo que sî refleja Gams ( $c f$. infra).

55 FUENTE, V. DE LA, op. cit., II, p. 201, n. 2.

Cincuenta at̃os

Hispania Sacra 49 (1997) 
puede restársele mérito ni por su atrevimiento ni por su gran erudición, algo que olvida de la Fuente.

Entre las páginas 34 y 36 del tomo II, 2, de su Kirchengeschichte von Spanien $^{56}$ y después de exponer esa intervención de Gregorio Magno en Spania a partir de lo que expresamente se puede entender de la documentación disponible, Gams aborda un breve análisis sobre la atención que se había prestado a este asunto por parte de otros autores: comienza por la obra de Aguirre ${ }^{57}$, donde no encuentra ninguna discusión sobre el particular -tampoco encuentra nada en sus seguidores- y concluye precisamente con la obra de Enrique Flórez deteniéndose en los parágratos que en el tomo XII de su España Sagrada dedica el agustino a exponer los datos por los que consideraba falsa la sentencia que Gregorio Magno entregaría a su Defensor Juan.

Habla Gams, resumiendo a Flórez, de esa Disertación que había provocado las dudas del agustino pero tampoco el autor alemán menciona en ningún momento su título o a su autor ${ }^{58}$. Gams continúa resumiendo los argumentos que llevaron a Flórez a cuestionar la autenticidad de esos «capitulares» discutiendo a su vez los mismos y concluyendo siempre con una postura contraria a la de Flórez; por ejemplo, para el caso concerniente a Ianuarius termina su exposición con "Was aber Florez gegen die Aechtheit der Sentez des Defensor Johannes vorbringt, ist für mich nicht überzeugend ${ }^{59} \mathrm{e}$ igualmente ante el argumento de Flórez de considerar indigno de Gregorio Magno el estilo con que se redactan esas cartas le contradice totalmente al indicar que considera las mismas totalmente dignas de la personalidad de ese pontífice ${ }^{60}$.

Pero sí debemos elogiar y agradecer el cuidado de Gams en discutir las propuestas de Flórez, debemos igualmente sorprendernos por el hecho de que en ningún momento mencione la Disertación de Pedro de Castro ni la breve exposición de Matías de Villanuño en defensa de la autenticidad de tales documentos. La ausencia de la obra de Pedro de Castro, y aín la de Villanuño, en el análisis de Gams, utilizando ambos -más farragosamente el primero- los mismos argumentos que un siglo después utilizará el alemán para rebatir a Florez, considero que únicamente puede entenderse desde el predominio historiográfico de Flórez y su España Sagrada no sólo a los ojos de los propios intelectuales españoles de la segunda mitad del siglo XVIII y el XIX sino también de aquellos extranjeros que se interesaron por la historia hispana. La

\footnotetext{
56 GAMS, P. B., Die Kirchengeschichte von Spanien I-II. Vom vierten bis Ende des eilfien Jahrhunderts (Jahr 305-1085). II. Von Jahr 589 bis 1085, Regensburg 1874, pp. 34-6.

57 SÁENZ DE AgulRre, J., Notitia Conciliorum Hispaniae, Salamanca 1686.

s8 Vid. también inmediatamente infra.

59 GAMS, P. B., op. cit., 35.

60 GAMS, P. B., op. cit., pp. 35-6.
} 
magna obra era la España Sagrada y en ella se fijó Gams -y sin duda otrospara analizar la atención que la intelectualidad hispana había prestado a la dominación bizantina de parte del territorio peninsular y del insular balear; no buscó $\longrightarrow$ o por lo menos no la debió encontrar- la disertación provocadora de la polémica pero tampoco fue más allá en la búsqueda de alguna obra que hubiera rebatido la arriesgada postura de Flórez. Y esa obra - u obras- existían: una era prácticamente contemporánea de la propuesta de Flórez- un año posterior- y además figuraba en la propia biblioteca del agustino, tal como aparece en el manuscrito conservado en la Biblioteca de la Real Academia de la Historia de Madrid y publicado por Custodio Vega en el Boletín de esa Institución ${ }^{61}$; la otra tampoco era desconocida puesto que era utilizada por los autores españoles que a finales de siglo se dedicaban, como el alemán, a estudiar la Historia de la Iglesia de España en época tardoantigua.

La segunda referencia a la disertación primera y a la propuesta de Flórez es obra de Paul Ewald en un largo artículo que se convirtió en el borrador sobre el que Hartmann, tras la muerte del primero, edificó su edición crítica en los MGH del Registrum Epistolarum gregoriano ${ }^{62}$. Ewald, y lo recoge Hartmann en el comentario inicial a la Epistola XIII, $49^{63}$, en función de su lectura de esas cartas incluidas en el Codex Matritensis habla de la existencia de una «Disertación sobre la verdad de las epístolas atribuidas a San Gregorio el Magno dirigidas a Juan Defensor», por lo que cabe pensar que esta Disertación de la que hablaba Ewald a finales del siglo pasado sería precisamente la que cita Flórez y no la de Pedro de Castro de 1755 porque no coincide el título ni tampoco la utilizaría Ewald para hablar de la falsedad.

Repasando las publicaciones más completas sobre este asunto, se observa que ni Fr. Görres ni P. Goubert, K. F. Stroheker o E. A. Thompson hacen mención alguna de este particular, no sólo porque no aluden en ningún momento a esta controversia tan propiamente dieciochesca sino porque el pleno y contextualizado uso que hacen en sus obras de los datos aparecidos en esas epístolas habla por sí sólo de la validez que otorgan a los mismos ${ }^{64}$.

\footnotetext{
61 Vid. supra.

62 EWALD, P., Studien zur Ausgabe des Register Gregors I, Neues Archiv III (1878) pp. 431-625.

63 La Epistola XIII, 49 de la ed. de Hartmann se corresponde con la XIII, 48 de la edición de NORBERG, D., Sancti Gregorii Magni Registrum Epistolarum (CCL, 140-140 A), Tumholt 1982.

64 GÖRRES, FR., Die Byzantinische Besitzungen an den Kïsten des spanisch-westgotischen Reiches (554-624), ByzZ 16 (1907) 514-38; GOUBERT, P., Byzance et l'Espagne wisigothique, REByZ II (1944) 5-78; Id., L'Administration de l'Espagne byzantine: les gouverneurs de l'Espagne byzantine, REByZ III (1945) 126-42; Id., Administration de l'Espagne byzantine, REByZ IV (1946) 71-133; STROHEKER, K. F., «Das Spanische Westgotenneich und Byzanz», Germanentum und Spätantike, Zurich 1965, pp. 207-15; THOMPSON, E. A., Los godos en España, trad. esp. Madrid 1971. Resulta también sumamente significativo que VEGA, A. C., El primado romano y la Iglesia española en los siete primeros

Cincuenta años

Hispania Sacra 49 (1997)
} 
Pedro de Castro y posterioremente Matías de Villanuño aciertan en muchos de sus argumentos defensivos de la legitimidad de estas cartas pontificias y sin embargo nadie alude a la Disertación del primero ni tampoco consiguió, como acabamos de ver, que Flórez le contestase; es lamentable que una obra tan documentada como ésta de Pedro de Castro, a pesar de lo complejo de su lectura aun para alguien del XVIII y de lo autoritario de su exposición, que recibe la censura favorable de la Real Academia de la Historia no tuviera difusión alguna en los estudios que sobre la Iglesia de la España Visigoda y Bizantina se hicieron a partir de entonces. Sin embargo la obra de Pedro de Castro, como lo demuestra el planteamiento que este episodio protagonizado por Ianuario y Esteban recibió en las obras posteriores, no cayó en saco roto ya que nadie pareció hacer caso a la propuesta de Enrique Flórez; tan sólo Villanuño, amén de Pedro de Castro, le presta atención. El cuestionamiento comenzó y acabó con el agustino pues ya nadie más dudó de la intervención de Gregorio Magno en asuntos de la Iglesia hispana sometida al dominio bizantino a finales del siglo VI; de hecho este episodio eclesiástico-político explica muchas de las posturas visigodo-bizantinas en la relación que mantuvieron en las últimas décadas del siglo vi y primeras del VII.

siglos, La Ciudad de Dios 154 (1942) 249-71, cuando estudia este episodio no haga ninguna mencion a este debate historiografico del siglo XVIII en el que se vio plenamente involucrado Flórez.

Cincuenta años Hispania Sacra 49 (1997) 